\title{
BOUNDLESS THOUGHT. THE CASE OF CONCEPTUAL MENTAL EPISODES
}

\author{
PIERRE STEINER
}

FNRS / Université Catholique de Louvain (Institut Supérieur de Philosopbie) (Belgium)

Université de Technologie Compiègne / Sorbonne Université (France)

60200 COMPIËGNE

FRANCE

Pierre.Steiner@uclouvain.be

\section{Received: 22.07.20II; Revised: 10.04.2012; Accepted: 07.07.20I2}

\begin{abstract}
I present and defend here a thesis named vebicleless externalism for conceptual mental episodes. According to it, the constitutive relations there are between the production of conceptual mental episodes by an individual and the inclusion of this individual in social discursive practices make it non-necessary to equate, even partially, conceptual mental episodes with the occurrence of physical events inside of that individual. Conceptual mental episodes do not have subpersonal vehicles; they have owners: persons in interpretational practices. That thesis is grounded on inferentialism and on the endorsement of the idea that "meaning is normative". After having recapitulated this heritage and after having presented that thesis, the paper especially attempts to articulate how, in that framework, we may then positively conceive the relations there are between conceptual mental episodes, intracranial events and inferential behaviour.
\end{abstract}

Keywords: Vehicles. Conceptual mental episodes. Inferentialism. Normativity. Mental content. Supervenience.

\section{INTRODUCTION}

\section{Wittgenstein once wrote:}

nothing seems more possible to me than that people some day will come to the definite opinion that there is no copy in either the physiological or the nervous systems which corresponds to a particular thought, or a particular idea, or memory $\left(1982, \int 504\right)$.

Manuscrito - Rev. Int. Fil., Campinas, v. 35, n. 2, p. 269-309, jul.-dez. 2012. 
This statement about the possible future of cognitive research is not an empirically-based statement. From a priori or conceptual reasons, Wittgenstein argued that it might be the case that some kinds of mental episodes might not have particular intracranial realizers (on the model of a one-to-one correspondence), without thinking that mental episodes had to belong, for that reason, to some specific, free floating, ontological realm ${ }^{1}$. Wittgenstein is not the only thinker that has jettisoned the presupposition that the occurrence of some mental episodes for an individual should necessarily be equated with the occurrence of internal physical properties inside of that individual. Philosophers such as Arthur Collins (1987), Lynne Rudder-Baker (1987), John McDowell (1998a, essay 13), Vincent Descombes (1995), Greg McCulloch (2003), Sonia Sedivy (2004) and Robert Brandom (2004) have shared a similar suspicion towards the localization of the realizers of mental episodes in the nervous system of the individuals that had these mental episodes.

Following the lead opened by these authors, I would like to propose here a systematic argument against the more precise idea that conceptual mental episodes (CME) such as judgments should have intracranial vehicles or realizers. Positively, and more originally (i.e. unlike the authors mentioned above), I intend to defend an alternative view called vehicleless externalism for conceptual mental episodes (VECME), that explicitly articulates what the relations between intracranial processes and $\mathrm{CME}$ amount to, if they are not realization-relations. This also requires being clear on what and where CME are (if not in the brain), and what their relations with behaviour are.

In the second part of the paper, I define what I mean by "conceptual mental episodes", "realization" and "vehicles", and sketch the Kampfplatz in which the argument I will propose here takes place.

\footnotetext{
${ }^{1}$ For variations around that Wittgensteinian theme, see Malcolm(1989), Kenny (1989), Hacker (2007).
}

Manuscrito - Rev. Int. Fil., Campinas, v. 35, n. 2, p. 269-309, jul.-dez. 2012. 
The third part locates the roots of my argument in the conjunction of inferentialism about content and normativism about content. I then present, in the fourth part, an externalist (and Brandom-inspired) account of the ontological status of CME that relies on their social and normative embeddedness. In the fifth and sixth parts, I show how, in that framework, we cannot and especially do not need to see intracranial processes as vehicles of $\mathrm{CME}$, and how one can give to these neural processes a more modest explanatory role to play in the production of intentional states and behaviour.

\section{CONCEPTUAL MENTAL EPISODES, REALIZERS AND VEHICLES: SETTING THE STAGE}

Conceptual mental episodes (CME) are tokens - spatiotemporal instances - of conceptual mental types. They are (personal-level) acts of thinking that $p$, where $p$ is truth-evaluable and conceptually articulated.

$\mathrm{CME}$ are intentionally directed on an object (existing or not), via their conceptual content. CME are conscious mental events. Beliefs are not CME: they are standing states that do not need to be manifested in consciousness. The paradigmatic kind of CME I will focus here is judgment. Judgment here primarily denotes the act of judging some content (what is judged). Judging some content consists here in putting two concepts into a relation, by predicating one concept of another. Judgments are the primary place of exercise of concepts: concepts are here defined as predicates of possible judgments, so that the fundamental sort of conceptual content is the content of judgments.

It is common to cast the problem of the relations between conceptual mental episodes and physical processes in terms of realization and realizers: do CME (paradigmatically: judgments) have physical realizers, including intracranially located physical realizers?

A realizer is the instantiation of a property or set of properties that is constitutively sufficient for the instantiation of another higherlevel property or set of properties (Shoemaker, 2007). If $P$ is a realizer

Manuscrito - Rev. Int. Fil., Campinas, v. 35, n. 2, p. 269-309, jul.-dez. 2012. 
of $M$, the conditional $P \rightarrow M$ holds with nomological necessity (Kim, 2003, p.577). But there is more than that, if one wants to see the realization relation as being more than a mere relation of correlation ${ }^{2}$ : the fact that $P$ realizes $M$ means that $M$ strongly supervenes on $P$ (the determination from $P$ to $M$ holds across all possible worlds), and that there is an explanatory connection between $P$ and $M$. As Kim remarks,

to have a physical realization is to be physically grounded and explainable in terms of the processes at an underlying level (1993, p.328)

According to vehicle-theories of CME, the realizers of CME are vehicles. One might figure a vehicle as what remains in one event of thinking that $p$ if one descriptively strips this event of all its intentional and phenomenal properties: a non-intentionally specifiable phenomenon is supposed to remain; this meaningless, subpersonal, and mind-independent bundle of material properties can be described and individuated with reference to its formal, syntactical, or physical properties. That is the vehicle. Even though it can be described and individuated with reference to its non-intentional properties, it is (supposed to be) a content-providing or content-bearing physical entity (Clark 2006; Rowlands 2003, p.156). We here understand the 'providing relation in two possible senses: either it might mean the vehicle encodes the very same content as the content of the CME, as it has the same formal structure as that content, or it might mean the vehicle encodes some content (at $t$ ) that causally explains the simultaneous presence of the personal-level (judged) content, without necessarily being a formally-conform translation of $\mathrm{it}^{3}$. In any case, it is by encoding content and by having some distinct functional role that the vehicle is

\footnotetext{
${ }^{2}$ We should also note that unlike the relations of correlation and identity, the relation of realization is non-symmetrical.

3 The first case applies to a symbolic conception of the vehicles of CME (the vehicles of CME are Mentalese sentences). The second case is proper to subsymbolic conceptions of the vehicles of CME.
}

Manuscrito - Rev. Int. Fil., Campinas, v. 35, n. 2, p. 269-309, jul.-dez. 2012. 
supposed to be the realizer of the CME. According to vehicle theories of CME, every time $S$ judges that $p$, there is a fact of the matter in or around $S$ that makes a difference with his not judging that $p$ (or his judging that $q$ ). This fact of the matter is the occurrence of the vehicle of the CME (in some cases modulo its functional role, or its relations with environmental variables). That occurrence of the vehicle is the truthmaker of the ascription "S judges that $p$ ".

For classical philosophy of mind, the realizers of CME at least include intracranial vehicles (hence vehicle-internalism). Vehicle-internalist theories of CME currently include the following positions:

(a) The realizers of CME are intracranial vehicles: intracranial vehicles are sufficient for the CME they realize, modulo some possible and appropriate functional role and some appropriate background and enabling conditions ${ }^{4}$. Type and token identity-theories (including functionalist theories) of CME are likely to embrace that option.

(b) The core realizers of CME are intracranial vehicles: intracranial vehicles are most readily identifiable as playing a crucial causal role in producing or sustaining the occurrence of CME, modulo some appropriate background and enabling conditions, and noncore parts of the realizers, that can be external to the system that entertains $\mathrm{CME}^{5}$. Externalist theories about content (relying on possible cases such as Putnam's Twin Earth, Davidson's Swampman...) will probably endorse

\footnotetext{
${ }^{4}$ States of affairs are background conditions to $P$ if variations in these states of affairs produce variations in $\mathrm{P}$. States of affairs are enabling conditions of $\mathrm{P}$ if the absence of these states of affairs prevents $\mathrm{P}$ from occurring. They are necessary for $\mathrm{P}$ to occur, but do not constitute the realization base of $\mathrm{P}$.

${ }^{5}$ Following Shoemaker (2007, p.21) and Wilson (2004, p.107-110), we may define the total realizer of a property as a property whose instantiation is sufficient for that property. A core realizer is a property whose instantiation is a salient part of a total instantiation of the property: the presence or the absence of the realized property is a function of the absence or of the presence of that core realize, while the non-core part of the total realizer is a relatively permanent property of the subject or even of the environment.
}

Manuscrito - Rev. Int. Fil., Campinas, v. 35, n. 2, p. 269-309, jul.-dez. 2012. 
that position, by considering that the total realizers of CME should include relational (causal, social, historical) properties between the thinker and her environment, so that two agents that are internally identical may nevertheless differ in the content of what they think. Still, that possibility is compatible with the fact that some intracranial vehicle remains the core realizers of the CME (McDowell, 1998a, essay 13; McGinn, 1982).

(c) The realizers of CME necessarily include intracranial vehicles: in that option, the core-realizers of CME may not be exclusively located inside of the individual who has CME. For externalists about content, there are some cases in which some kinds of thoughts (de re thoughts, for instance) literally include as constituents some of their objects. For some proponents of extended cognition, there are also some case in which the vehicles of complex CME, about numerals for instance, include material symbols and inscriptions (Clark, 2006).

For vehicleless externalism on CME, the realizers of CME do not include intracranial vehicles. Or better: CME globally supervene on embedded behavioural performances of persons that are the owners, and not the vehicles of these CME. These performances involve intracranial events, processes and parameters, but only mediately, so that we do not need and cannot see these intracranial phenomena as vehicles of CME.

\section{INFERENTIALISM AND THE NORMATIVITY OF MEANING}

Following some basic sense of the expression, almost nobody denies that meaning or conceptual content (including the content of what one thinks, or mental content) is normative ${ }^{6}$. For instance, it is a common principle that meaningful entities (paradigmatically linguistic representations) can be (assessed as) true or false, correct or incorrect

\footnotetext{
${ }^{6}$ Conceptual content can denote here both linguistic content and intentional content. I assume here - from a Kantian framework - that concepts are primarily exercised in judging. The fundamental sort of conceptual content is therefore propositional content.
}

Manuscrito - Rev. Int. Fil., Campinas, v. 35, n. 2, p. 269-309, jul.-dez. 2012. 
(Evans 1982, p.202; Brandom 1994, p.9; Fodor \& LePore 2002, p.153; Haugeland 1998, p.294). Similarly, many authors might accept, in a Davidsonian fashion that talk of propositional attitudes is intelligible only in the context of constitutive ideals of rationality shared by interpreters and interpretees. More broadly, the idea that "...means..." has some normative (notably pragmatic) consequences is not likely to cause many philosophical debates, provided it comes with the idea that this proposition is not in itself a normative proposition and that meaning is not in itself (aside from its consequences) normative (Jacob 1997, p.188).

A stronger reading of the "meaning is normative" statement is the following - and I will assume it here: there is no meaning prior to the norms that define this meaning. That is: meaning is constitutively normative. It is not only the case that means implies some oughts: more fundamentally, "for every means, there is an ought that implies it" (Gibbard 1994, p.101). Inferentialism can help us to better understand why meaning is (probably) constitutively normative. According to inferentialism, the meaning of an assertion or of some judgment supervenes on its inferential role in some linguistic system, including perceptual entries and behavioural exits. That inferential role is framed and constrained by inferential rules: rules pertaining to what one may and may not do when one asserts or judges some content. Inferential relations, broadly defined (including perception and action) exhaustively constitute the inferential role and thus the content of assertions and judgments. For the Kant-Frege-Sellars inferentialism we consider here, linguistic expressions and the conceptual contents of judgments are the primary semantic units from which the rules of use of a word or concept can then be conceived.

Classically, inferentialism considers that two important features of an expression (be it an utterance or a judgment) define its meaning: 1) The circumstances in which it is correct and non-correct to apply this expression - these circumstances can be inferential or noninferential (perceptual). For instance, it is correct to apply the 
expression "There is no more milk in the fridge" to some particular state of affairs (the absence of milk in the fridge) or as an inferential consequence of the expression "John has drained the last bottle of milk that was in the fridge" or of the visual experience of the current state of the fridge. It is non-correct to produce that expression as a consequence of the visual experience of the presence of milk in the fridge, or as a consequence of the expression "The fridge contains two full bottles of milk";

2) The appropriate and non-appropriate consequences of its application, which can be linguistic or non-inferential (action). For instance, it is appropriate to use the expression "There is no more milk in the fridge" as an inferential premise for the expression "One cannot take milk from the fridge" or for the action of putting some milk in the fridge. It is non-appropriate to use it as a premise for the action of inviting someone to take milk from the fridge.

Talking about correct and non-correct circumstances of application, and appropriate and non-appropriate consequences of use that define inferential role show how meaning is constitutively normative: inferential rules define the inferential role and thus the nature of the content of an expression. As the rules of a game, for instance, inferential rules do not prescribe what ought to be done, but what is allowed and what is not allowed to do. Saying that $q$ is inferable from $p$ is not saying that whenever $p$ is asserted, $q$ ought to be asserted, but rather saying that it is incorrect to assert $p$ and deny $q$, and that it is allowed to infer $q$ from $p$ (Peregrin, 2006).

Crispin Wright has well defined one important epistemic consequence of the idea that meaning is normative:

Meaning is normative. To know the meaning of an expression is to know, perbaps unreflectively, how to appraise uses of it; it is to know a set of constraints to which correct use conform (1987, p.24; my emphasis) 
According to the normative inferentialist framework we assume here, knowing the meaning of an expression (understanding it) is mastering its normatively-framed inferential role. The mastery of some content is basically a practical ability to respond differentially to correct and noncorrect inferences from this content, and thus a practical knowledge of what would be implied from it as a premise (another content, or some action), or of what may serve for justifying it as a conclusion (another content, or a perceptual experience). That ability to act following these inferential rules is a constitutive condition of the genuine mastery by that agent of the meaning or of the conceptual content defined by these rules. In other words, in order for some agent to judge that $p$, she must practically know what follows from the judging of $p$, and what it follows from ${ }^{7}$. That practical knowledge may take the form of dispositions to produce some contents that inferentially follow from $p$ or from which $p$ inferentially follows, of dispositions not to produce the contents that are incompatible with $p$, or of dispositions to correct deviant uses of $p$ by other agents (in applications and inferences, for instance). In any case, the intentional agent must have some sensitivity to the inferential rules that give the nature of the conceptual concept that is used. He must be disposed to think, speak and act in specific ways. John McDowell clearly expresses that requirement on understanding and knowing meaning:

We find it natural to think of meaning and understanding in, as it were, contractual terms. Our idea is that to learn the meaning of a word is to acquire an understanding that obliges us subsequently - if we have

7 Defining the Generality Constraint, Gareth Evans (1982, pp.100-105) also argued that understanding a thought is a structured ability that systematically presupposes connections to other thoughts and propositional attitudes. Stephen Stich, in a famous example (the McKinley case), also defended that idea (Stich, 1983, pp.53-57). Still, we must note that these two authors would not (have) probably endorse(d) the basics of inferentialism concerning the nature of conceptual content itself (and not only of its mastery).

Manuscrito - Rev. Int. Fil., Campinas, v. 35, n. 2, p. 269-309, jul.-dez. 2012. 
occasion to deploy the concept in question - to judge and speak in certain determinate ways, on pain of failure to obey the dictates of the meanings we have grasped (1998b, p.221).

In order to correctly use $p$, we are not obliged to judge and speak some specific content, we are rather obliged to judge and speak in certain determinate ways: these ways are just constraints that define the meaning of $p$. Typically expressed by conditionals - material or formal inferential rules do not prescribe what ought to be done, but what is allowed and what is not allowed to do when one asserts or judges that $p$. Inferential rules do not primarily consist in commands, obligations or incentives for speakers or believers; they rather constrain our linguistic practices by delimitating what, on an inferential point of view, we may and may not do by entertaining conceptual contents ${ }^{8}$ (Sellars, 1974; Peregrin, 2006). These moving and contextual constraints we abide ourselves by define the space in which meaning and expressive liberty may therefore appear (Brandom, 1979). This is a basic difference between normative and natural constraints (Brandom, 2004, p.248).

\section{A SOCIAL VERSION OF NORMATIVE INFERENTIALISM}

As seen in the former section, to have a concept is to make oneself responsible to certain norms or standards of correctness, defined by inferential rules. If a speaker means something by a general term, then the speaker has adopted a rule that specifies the standards of correctness for the term as she proposes to use it. That stance must be a social stance, for many reasons. First, the rule must fit with the rules used by other speakers, since the use of the term or of the concept notably serves communicative purposes. Following a rule is thus, minimally, being in step with other language users. Second, how can I know that I follow a rule specifying the standards of correctness for the

\footnotetext{
${ }^{8}$ Saying that concept use is rule-regulated is not necessarily saying that this use is completely specifiable in terms of explicit rules (Lance, 2000).
}

Manuscrito - Rev. Int. Fil., Campinas, v. 35, n. 2, p. 269-309, jul.-dez. 2012. 
terms that I use? Since Wittgenstein, we know that there is an irreducible difference between thinking one obeys a rule and obeying a rule. Indeed, one cannot obey a rule privately (Wittgenstein, 1953, \ 199, S 202). The only way I may know if I correctly apply a rule is by referring to the way other members of the practice treat my linguistic behaviour when we participate together in the institution of language. This implies that all members of a linguistic practice (even myself) entertain normative attitudes (sanctions, rewards, corrections,...) towards the conceptual behaviour of others: the fact that I can ensure that a rule is respected can, moreover, constitute a criterion of the fact that I respect it. Social interactions therefore constitute the medium in which rules are applied by individuals. But that's not all. Indeed (and this is the third reason why following a rule is a social stance), rules (including inferential rules) cannot exist without people following them and having instituted them. Normativity is grounded and exercised in virtue of attitudes such as instituting, obeying, sanctioning, rewarding, and correcting. Fourth, in order to be applied by some individual, these rules must be learnt. Social interactions also provide the medium for learning (Sellars, 1963, chap.11).

Robert Brandom has recently developed a full-blown inferentialist and social understanding of what it is to assert and to judge content. As seen above, inferentialism classically considers that two important features of an expression define its meaning: the circumstances in which it is correct to apply this expression, and the appropriate consequences of its application. In Brandom's framework, these appropriate circumstances and consequences of use are defined in terms of commitments and entitlements. Commitments and entitlements are defined as normative statuses, which are the objects of three types of normative attitudes: acknowledgment, undertaking, attributions. It is in social practices of deontic scorekeeping that scorekeepers acknowledge, undertake and attribute commitments and entitlements that define the inferential role of the conceptual contents of judgments, but also the conditions of having them.

Manuscrito - Rev. Int. Fil., Campinas, v. 35, n. 2, p. 269-309, jul.-dez. 2012. 
More precisely, there are three basic kinds of normative statuses one inherits by asserting or judging that $p$ :

- Commitment. Assertions and judgments commit us to other claims. By committing myself to This apple is red (by asserting or by judging it) I also commit myself to This fruit is red.

The normative status of commitment can be mapped onto deductive semantic relations. That is, $S$ 's judging that $p$ commits her to the endorsement of $q$ if $q$ may be formally or materially deduced from $p$. Commitment-preserving inferences are deductively good inferences generalized to the case of material inferences.

- Entitlement: Assertions and judgments have premises and justifications. But they can also be offered as reasons and premises for justifying other claims. By being committed and entitled to This apple is red I am for instance entitled to (be committed to) This apple is ripe. The normative status of entitlement can be mapped onto inductive and supporting semantic relations. That is, $S$ 's judging that $p$ entitles her to $q$ if $q$ may be induced from $p$ (commitment to $p$ can be invoked as sufficient justification of commitment to $q$ ). Entitlement-preserving inferences are inductively good inferences generalized to the case of material inferences.

- Precluded Entitlement. Assertions and judgments also stand in incompatibility relations with other claims. Being committed to This apple is red precludes one from being entitled to claim that This apple is green. The normative status of precluded entitlement can be mapped onto incompatibility relations. That is, two claims or judgments are incompatible if commitment to one precludes entitlement to the other (commitment to $p$ does not entail entitlement to $q$; commitment to $q$ does not entail entitlement to $p$ ).

Inferential relations are here thought in terms of preservation, inheritance and exclusion relations among acknowledged and attributed commitments, entitlements and precluded entitlements.

Asserting or judging that $p$ is undertaking commitment to $p$, by acknowledging that content: one may or may not be entitled to this Manuscrito - Rev. Int. Fil., Campinas, v. 35, n. 2, p. 269-309, jul.-dez. 2012. 
commitment (as reasons can be asked for it), but one also inherits other commitments and entitlements (and precluded entitlements) to inferentially-related contents by acknowledging commitment to $p$. That inheritance is realized in virtue of implicit (or possible explicit) attributions of these deontic statuses (commitments, entitlements, precluded entitlements) by members of the linguistic community, themselves exercising normative attitudes towards commitments (undertakings, attributions, acknowledgments). The content of the commitments, which scorekeepers undertake by acknowledging these commitments (by asserting or judging, for instance) is notably defined by the commitments that are inherited from these commitments and that are implicitly attributed by other scorekeepers. As we will see, one consequentially undertakes these inherited commitments.

To sum up, in Brandom's perspective, the content of what we say and judge is inferentially articulated by being pragmatically determined in normative practices of scorekeeping. Conceptual content that is judged is constituted by what we implicitly do when we are judging it, namely undertaking commitments to the basic inferences that articulate the nature of this content, and that ideally, we should minimally endorse (acknowledge) by not rejecting their correctness when prompted. Consequently, understanding or mastering some content is being able to tell what one is thereby committing himself to (what follows from $p$ ), what evidence would entitle one to it (what $p$ follows from), and what is incompatible with it (Brandom 2008, 79-80).

Social practices of scorekeeping confer content to performances; they institute and exercise the normative statuses (commitments, entitlements) defining how it is correct to use expressions, under what circumstances it is appropriate to produce some conceptual performances and what the appropriate consequences of these performances are. The crucial point here is that these statuses do not primarily or centrally supervene on inner physical properties of their owners. They are attributed or attributable by other scorekeepers in social practices of giving and asking for reasons, whose building

Manuscrito - Rev. Int. Fil., Campinas, v. 35, n. 2, p. 269-309, jul.-dez. 2012. 
blocks are acting and talking persons, and not what happens inside of them. Even when they are undertaken by being acknowledged by an individual, the significance of these normative statuses is always related to the attribution of the other statuses (commitments, entitlements) that are inherited from them and define their content. This point is not only crucial when we consider the contents of CME, it is central when we have to define what judging some content is.

\section{WHERE IS MY MIND? AGAINST VEHICLE-INTERNALISM FOR CONCEPTUAL MENTAL EPISODES}

It is common to conceive of conceptual mental phenomena on the model of propositional attitudes. According to that model, CME are composed of propositional contents (specified by "that..." clauses) that are the objects of various psychological attitudes (desiring, intending, fearing, judging...). One can fear that snow is white, one can desire that snow is white, and so on. The social and normative inferentialist understanding of what conceptual content is and how it is produced has crucial consequences when we have to define what judging some content is, even by preserving that basic model of propositional attitudes. If inferentialism and the idea that meaning is normative are correct, judging some content is not basically a psychological attitude, it is a normative attitude. As Collins (1987) argued, in judging that $p$, I do not report or describe some event - be it external or internal. Judging that $p$ is rather undertaking a commitment to (the truth of) $p$. This includes the fact that one acknowledges commitment to $p$. In Brandom's terminology, acknowledging is not necessarily avowing or asserting. Being disposed to avow, or to assert is already acknowledging (1994, p.194). Still, acknowledging commitment to $p$ is neither necessary nor sufficient for undertaking commitment to $p$. It is also non-sufficient for judging that $p$. Let us see why.

For undertaking commitment to $p$ by acknowledging commitment to $p$, I must not only acknowledge that $p$, I must be taken 
as being committed to $p$. Undertaking a commitment to $p$ is being taken as being committed to $p$, whenever others are entitled - in virtue of one's performances - to attribute to me that commitment (Brandom, 2002, p.220). They can do this on the basis of my ability to acknowledge some of the commitments I consequentially undertake by having acknowledged commitment to $p$, and that are attributed to me by other scorekeepers who are entitled to this attribution (Brandom, 1994, p.596). Indeed, the commitments other scorekeepers can attribute me can be the commitments I acknowledge (and that, in virtue of that attribution, become undertaken commitments), but also - and especially - the commitments I undertake consequentially, as consequences of acknowledged commitments (expressed in my sayings and doings), in the context of the prevailing norms (normatively instituted and pragmatically defined inferential connections) that define the inferential articulation and thus the content of what one says, judges, or does. The commitments one consequentially undertakes by acknowledging commitment to $p$ may go beyond the commitments one acknowledges (i.e is ready to assert). It is up to me to assert or judge something; it is not up to me what the consequences of that assertion or judgment are, and more basically what are the inferential rules that define its content. These consequentially undertaken commitments are therefore crucial for defining the supplementary conditions in virtue of which one can undertake a commitment by acknowledging it. As said above, undertaking a commitment is doing something that makes it appropriate for others to attribute it (Brandom 1994, p.162; 2000, p.174). This "doing something" can notably consist in being disposed to overtly acknowledge some of the commitments that consequentially follow from the commitment one has acknowledged. We must avoid a red herring here: there is no definite (i.e. eternal and non-contextual) number of inferential moves or relations that would be constitutive of the nature of some conceptual content and of its use (Brandom, 1994, p.636).

Manuscrito - Rev. Int. Fil., Campinas, v. 35, n. 2, p. 269-309, jul.-dez. 2012. 
These dispositions are not here factual or descriptive states of individuals: they are parts of normative practices, in which agents committed to $p$ (who acknowledge that commitment) should act in certain ways, conforming to the incentives of rules that define the content of $p$. For undertaking commitment to $p$ by acknowledging commitment to $p$, one must acknowledge some of the consequential commitments inherited by acknowledging commitment to $p$. It is only in virtue of that acknowledgment of inferentially related content that one can be taken as being committed to $p$, by acknowledging it.

Let us mention again the idiom of propositional attitudes: according to the argument presented above, for a psychological attitude to count as an attitude of judging that $p$, one must be ready to judge or to acknowledge some of the contents that inferentially define the meaning of $p$, and to which one becomes committed by judging that $p$. For instance, a psychological episode of muttering to oneself (in foro interno) this paper is boring can only count as an episode of judging that this paper is boring if one undertakes commitment to the proposition "this paper is boring". In order to do so, one must be ready to acknowledge (by judging) some of the contents one becomes consequentially (in virtue of inferential rules and attributions by scorekeepers) committed to by acknowledging that this paper is boring: for instance, one should be disposed to judge that in some ideal situation, this paper would deserve to be put in the trash, or that one is losing one's time. One must also be ready not to endorse commitments that are incompatible with that commitment, as in judging that this paper is exbilarating.

It is important to note that a) my acknowledgment of the consequential commitments inferentially related to the commitment to $p$ that I acknowledge, b) the attribution of commitments that consequentially follow from my acknowledgment of commitment to $p$, and c) the attribution of commitment to $p$ by scorekeepers (so that I can be taken as being committed to it), on the basis of my acknowledgment of the consequential commitments mentioned in (b), 
do not need to pass by explicit contentful performances to be effective, and thus for me to undertake commitment to $p$ by acknowledging that commitment. Indeed, a) acknowledging is not necessarily asserting or avowing; it can merely be being disposed to assert or avow, b) consequentially undertaken commitments are first defined in virtue of the prevailing inferential norms that exist in some linguistic community; other scorekeepers - actual and virtual - then expect us not to go against these commitments, minimally by expecting us to exhibit dispositions to sanction potential inappropriate conceptual behaviour (such as failures to acknowledge these consequential commitments that define the content of what one says, does or judges), c) attributions of commitments to $p$ (that is, being taken as being committed to $p$ ) on the basis of the acknowledgment of some of the consequential commitments that follow from $p$ do not need to be (and, indeed, are rarely) explicit, in the form of propositional attitudes ascription: they can be merely virtual, and thus only consisting in some possible attribution made by an omniscient scorekeeper to the agent under consideration, on the basis of her acknowledgment of some of the consequential commitments.

The reason why acknowledging commitment to $p$ is nonsufficient (but necessary) for judging that $p$ is related to the reason why acknowledging commitment to $p$ is non-necessary (and non sufficient) for undertaking commitment to $p$ is: in both cases, by acknowledging commitment to $p$, one undertakes commitment to contents that go beyond $p$, and that are inferentially related to $p$, whether one knows and likes it or not. If one wants to judge that $p$, one must acknowledge commitment to $p$, but must also acknowledge some of the consequential commitments one undertakes by acknowledging that $p$.

As the Wright and McDowell quotes exemplified it in the above section, acknowledging some or enough of the commitments (q) that consequentially (and "ascriptionally") follow from the acknowledged initial commitment $(p)$ is a decisive criterion for being taken as exbibiting the mastery of the inferential articulation of $p$, and thus for being taken as being committed to $p$ (and

Manuscrito - Rev. Int. Fil., Campinas, v. 35, n. 2, p. 269-309, jul.-dez. 2012. 
therefore for genuinely acknowledging p). Even when they are overtly acknowledged by an individual, the presence of commitments is always related to their possible attribution by other scorekeepers and, more fundamentally, to the attribution (by other scorekeepers as well) of other statuses that follow from these acknowledged commitments and that define their content, but also the conditions of their having: acknowledging some of the consequential commitments of $p$ is a good criterion for being taken as being committed to $p$. Agents are entitled to expect me to be committed to the range of actions and contents that inferentially follow from the initial commitment I acknowledge. If I fail to satisfy some of these expectations by not acknowledging them in my actions, utterances, or dispositions to act and say, then they can refuse to attribute to me the initial commitment, so that I do not undertake it, even if I acknowledge it and attribute it to myself (Brandom, 1994, p.554).

Let us draw the conclusions of this approach for judgments.

Judging that $p$ is not only (in foro interno) acknowledging that $p$; it is also acknowledging (in the dispositional sense!) the circumstances in which one becomes committed or entitled towards $p$, but also the consequential commitments and entitlements one inherits by being committed to $p$. It is on the basis of that acknowledgment that one can be taken as being committed to $p$, and can thus genuinely judge that $p$. Put otherwise, for judging that $p$ by acknowledging commitment to $p$, one must also be taken as being committed to $p$ : one does that by acknowledging some of the normative statuses that consequentially follow from his acknowledged commitment to $p$ and that inferentially define the content of his judgment (in one's linguistic community). It is not actual interpretation or attribution that matter here, but interpretability: being interpretable as acknowledging some of the inferential consequences of $p$ is enough for being (potentially) taken as judging that $p$. Judging that $p$ widely supervenes on embedded, personal and behavioural facts, occurrent and dispositional. These facts are 
inferential dispositions, dispositions to use $p$ in the game of giving and asking for reasons (Sellars 1963; Brandom 2000).

How much of that story is or should be compatible with vehicleinternalism on CME? And how does VECME conceive the relations there are between intracranial events, behavioural performances and CME? The next section will be devoted to these issues.

\section{BRAIN, BEHAVIOUR AND CME: DO WE NEED INTRACRANIAL VEHICLES?}

According to VECME, the presence (or the report of the presence) of some complex intracranial contentful event could neither constitute one's undertaking commitment to $p$, nor support its attributed or attributable presence. Indeed, undertaking commitments (and consequently, conceptual mental episodes) is a personal and sociallyembedded act, not an internal event of persons or of their brains. Talk of normative statuses and normative attitudes necessarily places us in the framework of an ontology in which persons and social practices are the basic building blocks. According to Brandom, by relying necessarily on intracranial and subpersonal parameters for defining what it is to judge some content, vehicle internalism on mental states is unable to explain

why some event's befalling a non-intentionally specified vehicle - say, an inscription being placed in the 'belief box' - should amount to endorsing a claim about how things are, to undertaking a commitment to things outside the believer being thus-and-so. To take this question seriously is to ask in what sense of "inner" beliefs can coherently be understood to be inner, given that believing includes adopting a normative stance or attitude toward the external world. (Brandom 2004, p.244; author's emphasis) ${ }^{9}$.

\footnotetext{
9 According to vehicle-internalism, non-intentionally specifiable intracranial entities stand to CME as non-intentionally but formally or syntactically specifiable material entities stand to linguistic signs. But the analogy fails, since in the case of CME, the supposed relata (intracranial processes and CME) exist at different levels: linguistic signs can be considered either as meaningful
} 
What constitutes the normative essence of the gain or loss of commitments cannot be deduced or predicted by observing intrinsic properties of their owners (although, as we will see, changes in normative statuses can covary with changes in physical states). Intracranial entities (non-intentionally specifiable vehicles) impose no normative consequences on the possession of present or future conceptual mental episodes or acts. But there is (much) more than this explanatory irreducibility of CME in relation with intracranial events and processes. Indeed, this explanatory irreducibility is still compatible with the possibility that intracranial events could be partial (necessary, but nonsufficient) realizers of CME.

Logically (i.e. at the level of the logic of our predicative attributions), undertaking commitments and endorsing claims are first proprieties of persons embedded in social practices, and not natural or material properties that could be instantiated in subpersonal inner events. In the Brandomian framework, organs and subpersonal vehicles cannot be vehicles of commitments not (only) for factual reasons, but basically because it is persons in social practices that undertake, attribute or acknowledge them. As Norman Malcolm argued,

it is only of a living creature that we can say that it manifests those complex patterns of behaviour and reaction within the ramifying context of a form of life that constitute the grounds, in appropriate circumstances, for the ascription of the network of psychological concepts. (in Armstrong \& Malcolm 1984, p.80)

entities or as sign-designs, at the same level, the personal level, where persons manipulate, design and manufacture them (and endow them with meaning, in virtue of instituted normative practices), whereas $\mathrm{CME}$ and the performances that come with them phenomenally exist at the (inter)personal level, in deontic practices of scorekeeping, while their (alleged) vehicles are manufactured (in an uncontrolled way!) at the subpersonal level, which is not a part of our deontic practices of scorekeeping: when I attribute CME to some agent, I make no hypothesis at all about something that would be in his head.

Manuscrito - Rev. Int. Fil., Campinas, v. 35, n. 2, p. 269-309, jul.-dez. 2012. 
If the brain can exhibit responses to various states of affairs, these responses do not constitute the conceptual responsibilities and commitments we undertake. Brains do not do what persons do (namely, engaging in social practices). Conversely, persons do not do what brains do (namely, causally enabling the production of intentional behaviour). It would therefore be a category (logical) mistake to equate CME, as personal events, with intracranial processes and events, as subpersonal phenomena - just like it would be a mistake to identify the act of giving with the hand movements that are involved in it ${ }^{10}$.

From explanatory and logical points of view, we have just seen that intracranial events and processes could not be the realizers of CME. From an ontological point of view, we can now see that it is not necessary to consider intracranial events and processes as vehicles or realizers (even partial) of CME. Indeed, we may now sketch an alternative picture of the relations existing between $\mathrm{CME}$, intracranial processes and behaviour. For that purpose, Malcolm's remark quoted above is helpful, if we distort it a little: complex patterns of behaviour (occurrent and dispositional) - here, inferential dispositions constitute the grounds or the logically adequate criteria for the attribution of commitments in appropriate circumstances: circumstances where social practices of deontic scorekeeping exist, and where that behaviour is seen as an adequate criterion of the existence of CME. Having CME is not a matter of intracranial vehicles or of mere dispositional states; it is a matter of being attributed a social status (commitment); this (actual or potential) attribution is notably based on our ability to exercise some inferential dispositions proper to the

10 As Wittgenstein remarks, "« Why can't my right hand give my left hand money?--My right hand can put it into my left hand. My right hand can write a deed of gift and my left hand a receipt.--But the further practical consequences would not be those of a gift. When the left hand has taken the money from the right, etc., we shall ask: "Well, and what of it?"» (Wittgenstein 1953, \268).

Manuscrito - Rev. Int. Fil., Campinas, v. 35, n. 2, p. 269-309, jul.-dez. 2012. 
inferential rules defining the content of the acknowledged and attributable commitment that constitutes the event of judging that $p$.

Acknowledging some of the commitments that consequentially follow from the acknowledged initial commitment is a good criterion for being taken as exhibiting this inferential mastery, and thus for being taken as being committed to $p$. Behavioural performances (occurrent and dispositional) are here criteria that ground the attribution of commitments (and thus, mediately, of CME); they are not the symptoms or the causes of these CME. Following Wittgenstein's distinction, symptoms are empirical evidences; they support a conclusion through theory and induction. A criterion $B$ for a claim $P$ is a ground or reason for the truth of $P$, not in virtue of empirical evidence, but of grammatical rules or internal relations. It is part of the meaning of $P$ and $B$ that $B$ 's being the case is a ground or reason for the truth of $P$ (Wittgenstein, 1958; Kenny, 1989, p.5). Translated in the inferentialist idiom, we would have the following example of criteria:

The dispositions to assert that $q$ and to produce action $Q$ are good criteria for being taken as committed to $p$ and thus for having undertaken commitment to $p$ by having acknowledged it in judgment, following the prevailing inferential norm according to which commitment to $p$ entails commitment to $q$ and to $Q$, and following the possible attribution of these commitments by other scorekeepers.

Attributing commitments to agents is expecting them to act in particular ways: we attribute to them the ability to exhibit some inferential behaviour that defines the content of the commitment we take them to be committed to. From this perspective, intracranial events do not cause the occurrence of CME; rather, they contribute to cause the occurrence of the behavioural abilities and performances (which are only correct or appropriate as embedded in some particular linguistic community) on the basis of which commitments may be attributed to the agent. From this perspective, the brain is not a mental organ, the recipient of CME. It is rather like a muscle that plays a crucial causal role in the production of the behavioural criteria on which the

Manuscrito - Rev. Int. Fil., Campinas, v. 35, n. 2, p. 269-309, jul.-dez. 2012. 
potential attributions of CME are anchored. Literally, of course, brains are definitely not muscles. They carry information; they are made of neurons and axons. Muscles are not. Still, regarding the production of the intentional behaviour of human agents, the position we sketch here makes intelligible the idea that brains play the same kind of explanatory role as muscles: they cause and constrain the ability to produce, and the production of, intentional behaviour. Muscles cause behaviour, but do not carry or realize the conceptual mental episodes that we can attribute on the basis of behaviour. It is the same for brains: they do not encode or realize conceptual mental episodes; they causally support the behaviour from which commitments can be attributed.

Let us sketch that picture in greater detail. Its primary aim is to suggest how we may not need to see intracranial processes as vehicles of CME, without denying their important role in the production of CME.

\section{Embedded behavioural performances and dispositions}
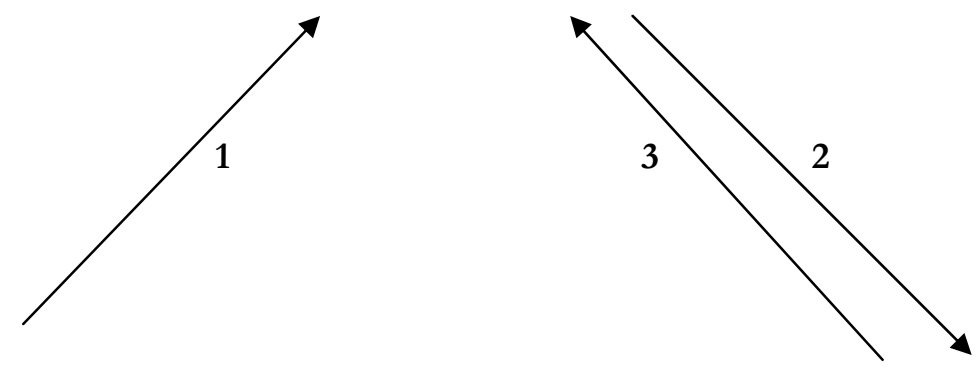

Intracranial processes

Conceptual mental episodes

4

(1) Neural events are among the most important mechanical causes of the existence and production of embedded behavioural performances and dispositions that serve as reliable criteria for the possible or actual attribution of commitment to $p$ to some agent, and thus for the fact 
that the agent can be taken as being committed to $p$ and judge that $p$ by acknowledging that $p$. These behavioural performances and dispositions are appropriate for the attribution of commitment to $p$, and are thus criteria for that attribution only because they are embedded in linguistic social practices, in which they can be assessed as appropriate or not by other agents, and in which they have as objects the commitments that consequentially follow from the acknowledgment of $p$, in virtue of the prevailing inferential norms of the linguistic community.

Brain processes do not influence our attributions of CME. Obviously, they causally influence the behavioural capacities and performances of agents on the basis of which these agents are interpretable as undertaking commitments and thus, as producing judgments. But behavioural skills are criteria for the interpretable presence of $\mathrm{CME}$ not because they are causally produced by intracranial operations, but because of our conceptions of what must contextually be the behavioural criteria of the presence of a CME. True, sometimes neuropsychological damages may cause behavioural deficiencies that can be taken as inferential deficiencies (think for instance about the case of aphasia). But what causes the deficiency does not directly constitute the rightness or wrongness of the deficient behaviour and even less the consequent fact that one judges or not that $p^{11}$. Rightness or wrongness are first related to the ways we will interpret the inferentially-deficient behaviour. In some cases, by knowing the causal origins of some inappropriate behavioural inferential performances, we may nevertheless attribute $\mathrm{CME}$ to agents. For instance, aphasic

11 Wittgenstein elegantly expresses that point: "Even if we knew that a particular area of the brain is changed by hearing God Save the King and that destroying this part of the brain prevents one's remembering the occasion, there is no reason to think that the structure produced in the brain represents God Save the King better than Rule Brittania" (1988, p.90). 
subjects, able to practically recognize and use objects, but unable to make interlinguistic moves (such as providing definitions or make inferences) with the concepts of these objects (Riddoch and Humphreys 1987), are not necessarily considered as unminded creatures, incapable of producing judgments, unlike for instance parrots or thermostats although the latter ones might exhibit impressive recognitional capacities, at least as good as the aphasic agents.

Behavioural deficiencies might put into question the fact the agent really entertains some judging or asserting only depending on our interpretations and attributions - and not from what the brain or the behaviour would directly show us. The relation between CME and neural events is thus indirect; it is behaviourally and environmentally mediated. The identification of the neural support of some CME is actually dependent on the previous identification and attribution of that $\mathrm{CME}$ in relation to behavioural criteria. In any case, neural events are not representational events that realize CME.

(2) The behavioural performances and dispositions of agents are probably the best conceptual supports for the attribution to these persons of commitments to the contents of their CME. Judging that $p$, my inferential and behavioural dispositions to practically endorse or assert commitments consequentially related to $p$ reveal the fact that my acknowledged commitment to $p$ is authentic (it amounts to undertaking commitment to $p$ ). It is crucial to note that the thesis defended here does not consist in defining or reducing $\mathrm{CME}$ to behavioural performances and dispositions, as logical or analytical behaviourism. CME have properties (phenomenal, intentional, biographical...) that go beyond behavioural performances and dispositions, although these performances and dispositions provide the best criteria for attributing the commitments that define these CME - but only as embedded in social and linguistic practices.

Manuscrito - Rev. Int. Fil., Campinas, v. 35, n. 2, p. 269-309, jul.-dez. 2012. 
(3) It is important to keep in mind a distinction between (a) the commitment I acknowledge when I judge that $p$; (b) the commitments I consequentially undertake in virtue of my acknowledging commitment to $p$ and in virtue of the prevailing inferential norms of the community; (c) some commitments belonging to (b) that I acknowledge, so that I may be taken as undertaking commitment to $p$ by acknowledging it $^{12}$. In both (b) and (c), no explicit attribution of commitments is required: all that matters is possible interpretation, grounded on behavioural performances and dispositions: performances and dispositions having as objects some of the commitments defined in (b).

What matters here is that the commitments defined in (b) and (c) must be assumed to come in cluster if one wants to see behavioural performances and dispositions as criteria of the presence of CME: if I explicitly acknowledge one of the commitment defined in (b), I can be taken as being committed to $\not$ provided I can acknowledge other (but not all) commitments defined in (b). One single behavioural performance or disposition, having as object commitment to one inferential consequence of (a) is never enough for serving as criterion for the attribution of commitment to $p \mathrm{I}$ acknowledge in case (a). Indeed, in order to see them as criteria of the presence of CME, one must assume that behavioural performances and dispositions are embedded in a network of commitments. The behavioural performances and dispositions having as object (c) and that support actual or possible attributions of the commitment acknowledged in (a) is a behaviour we see from the background of a network of commitments (b) that are attributed to the interpreted person, notably in order to make sense of the rational character of his behaviour. This is a classical Davidsonian point:

Beliefs are identified and described only within a dense pattern of beliefs. I can believe a cloud is passing before the sun, but only because I believe there is a sun, that clouds are made of water vapour, that

${ }^{12}$ As said before, the scope of (b) is necessarily wider than the scope of (c).

Manuscrito - Rev. Int. Fil., Campinas, v. 35, n. 2, p. 269-309, jul.-dez. 2012. 
water can exist in liquid or gaseous form; and so on, without end. No particular list of further beliefs is required to give substance to my belief that a cloud is passing before the sun; but some appropriate set of related beliefs must be there. If I suppose that you believe a cloud is passing before the sun, I suppose you have the right sort of pattern of beliefs to support that one belief, and these beliefs I assume you to have must, to do their supporting work, be enough like my beliefs to justify the description of your belief as a belief that a cloud is passing before the sun (Davidson, 1984, p.200).

Let us here seize the opportunity to make clear the relations between VECME and Davidson's anomalous monism (DAM). According to DAM, mental events are (token)identical with physical events and, more precisely, identical with intracranial physical events. Even though he defends content externalism and transcendental externalism (following the famous triangulation argument), Davidson still endorses vehicle-internalism (Davidson, 1987). DAM is thus a form of vehicleinternalism. Still, for Davidson, mental concepts and predicates are not reducible to physical concepts and predicates. The mental realm presents several features that "find no echo" in the physical domain (1980, p.231): holistic and normative dimensions of thought possession, externalism, non-existence of psychophysical and psychological laws (anomalousness), and so on. While VECME agrees with DAM that mental predicates are not reducible to physical vocabulary, and that holism, externalism and normativity are constitutive features of mentality, it parts ways with DAM on the question of the localization of CME, notably by radicalizing the importance of the normative and social dimensions of CME. In order to explain why, let us first note that it is well known that the account DAM proposes of mental causation is very controversial. One of the main premises of DAM is the idea that mental events causally interact with physical events (it is because a mental event can enter into a causal relation with a physical event that it is falls under a physical kind, and is thus a physical event (token physicalism)). Still, one cannot find in DAM arguments justifying how mental events can be causally

Manuscrito - Rev. Int. Fil., Campinas, v. 35, n. 2, p. 269-309, jul.-dez. 2012. 
efficacious in virtue of their mental character or, to put it simply, that mental properties are causally efficacious - hence the threat of (type)epiphenomenalism concerning mental properties in DAM (McLaughlin, 1989). It is not because events cause what they do however described (as Davidson claims, see for instance (Davidson, 1993)) that events cause what they do irrespective of the kinds or types of events they are (McLaughlin, 1993; Marras 2003, p.247). "Thinking causes" is the only essay where Davidson tried to explain how mental properties per se can be causally efficacious (Davidson, 1993). Davidson's answer - referring to weak supervenience - has not been successful to the eyes of many critics (Kim, 1993b, Sosa 1993, McLaughlin 1993). And even if the proponent of DAM could convincingly argue that mental properties are causally efficacious, she would then face the problem of causalexplanatory exclusion: how could the same event be caused both by mental and by physical properties (Kim, 1989, p.44)? Faced with these worries, Davidson has himself acknowledged that mental events "add nothing to the furniture of the world that is not treated in physics (though, of course, they do add a different way of describing and explaining what certain entities do)" (1999, p.654).

Still, what we see as an important problem in DAM is not (type)epiphenomenalism (or, at least, the acceptance of the fact that mental properties are not causally efficacious - as we will see in the conclusion, VECME does not share some of the premises that give rise to the problem of mental causation) but the consequences of the coupling between its (alleged, and sometimes explicitly acknowledged) (type)epiphenomenalism and its (acknowledged) vehicle-internalism. Locating mental events in the head and simultaneously accepting that mental properties per se are not causally efficacious opens the door to neurophysiological reductionism or eliminativism concerning mental properties and, consequentially, mental events: mental events are causally efficacious (and explanatorily relevant) only because mental properties are identical with physical properties. These reductionist and eliminativist options obviously go against one of the main objective of 
DAM: providing foundations for defining the autonomy of agency and will (1980, p.224) ${ }^{13}$. But how could that autonomy of human agency be saved by holding that $\mathrm{CME}$ are located in the intracranial realm, so that one cannot explain how mentality occurs and works except by identifying it with the physical properties and processes that constitute that realm (Kim, 1989)?

Defining CME as proprieties of persons embedded in social practices of deontic scorekeeping potentially allows one to better insist on the inextricability there is between CME, mentalistic explanations, and interpretative practices - up to the point where we may gain a new sense of their ontological status that is orthogonal to the controversy between (vehicle) internalist realism (such as DAM) and reductionism/eliminativism, and that could help us to understand how they might be causally efficacious on a explanatory level (see conclusion).

(4) With (1), (2) and (3) in mind, we can see that the relation between CME and neural goings-on is indirect, as it is behaviourally mediated. Moreover, it is only a causal (and indirect) relation. Neural events causally support the production of the behaviour that conceptually justifies the interpretation or interpretability of the person as entertaining some CME. For one thing, we do not attribute CME or assume their presence in people by looking at what there is in their heads. We assume their presence on the basis of behavioural criteria, without equating these CME with brute behavioural facts. Because of the key idea that intracranial processes and events are only mediately involved in the causal production and existence of CME, we do not need to see

\footnotetext{
${ }^{13}$ Davidson writes: “We explain a man's free actions, for example, by appeal to his desires, habits, knowledge and perceptions. Such accounts of intentional behavior operate in a conceptual framework removed from the direct reach of physical law by describing both cause and effect, reason and action, as aspects of a portrait of a human agent. The anomalism of the mental is thus a necessary condition for viewing action as autonomous" (1980, p.224)
}

Manuscrito - Rev. Int. Fil., Campinas, v. 35, n. 2, p. 269-309, jul.-dez. 2012. 
them as vehicles or realizers (partial or total) of CME. Actually, we might not even need to include them in the supervenience basis of the occurrence of CME. Following Klagge's distinction (Klagge, 1988), ascriptive supervenience is a connection between types of judgments expressing a conceptual requirement, while ontological supervenience is a connection between classes of properties, expressing a metaphysical necessity. Unsurprisingly, VECME assumes that possible or current judgments about the presence or absence of CME (ascriptively) supervene on judgments or reports on socially embedded behavioural facts (occurrent or dispositional). Still, as Klagge remarks, the ascriptive supervenience of mental judgments on behavioural judgments is compatible with the ontological supervenience of mental events on brain events (Klagge 1988, p.466). The ascriptive supervenience of mental judgments on behavioural judgments is not sufficient for defining the core of VECME. The ontological supervenience VECME should assume is the following one: conceptual mental properties (and, especially, their occurrence in CME) supervene on behavioural properties, more precisely behavioural properties as described and individuated in the social practices they are embedded in. The supervenience basis of CME consists in embedded (relational and normative) behavioural facts. As stated in section II, (ontological) supervenience is neither realization nor identity ${ }^{14}$. "CME supervene on embedded behavioural facts" means: there is no change in CME without changes in embedded behavioural dispositions and performances.

\footnotetext{
${ }^{14}$ Supervenience is not identity, so that there is no identification of CME with behaviour here (besides the fact that behavioural facts are here necessarily relational). Supervenience is not realization either: in order to amount to realization, supervenience of $\mathrm{M}$ on $\mathrm{P}$ must be strong (the determination from $P$ to $M$ holds across all possible worlds), and there must be an explanatory relation between $P$ and $M$ (see section II). Behavioural facts, here, could only explain the occurrence of CME if they are considered from their embedded (social, historical, biographical) dimensions, so that the explanation would not be on the classical nomological-deductive mode.
}

Manuscrito - Rev. Int. Fil., Campinas, v. 35, n. 2, p. 269-309, jul.-dez. 2012. 
These embedded behavioural changes often requires intracranial changes, but not necessarily: if inferential norms or social practices of deontic scorekeeping change, the conditions of possession of the concepts that constitute CME will change as well, and so will the fact that one entertains (or not) some thoughts (even if intracranial processes and parameters remain constant). Publicly observable inferential behaviour (as caused by intracranial processes) is one of the constituent elements of the occurrence of CME: CME primarily supervene on behavioural facts, embedded in an environment of linguistic institutions and of social practices of deontic scorekeeping.

More generally, enabling conditions are not the vehicles or realizers of what they enable to realize: here, brain processes but also artifacts (logical rules, inscriptions...) notably enable the production of inferential behaviour, and thus mediately enable the realization of $\mathrm{CME}$, but they are not the vehicles of CME. Embedded behavioural facts are causally dependent on intracranial processes, but the causal dependence of $\mathrm{Y}$ on $\mathrm{X}$ and the supervenience of $\mathrm{Z}$ on $\mathrm{Y}$ does not make that $\mathrm{Z}$ is realized or supervene upon $\mathrm{X}^{15}$.

\section{CONCLUSION}

Is VECME an ontological position? Yes, if one considers it assumes the existence and the reality of conceptual mental episodes. For VECME, it makes sense to ask what their supervenience basis is. But if one means by 'ontological' any approach that aims at defining the existence of conceptual mental episodes by referring to facts of the matter (as pure physical facts) that are not related to our ways of defining and

\footnotetext{
${ }^{15}$ For instance, the possible fact aesthetic properties supervene on the physical properties of their medium as they are embedded in some institutional world does not imply aesthetic properties supervene upon or are realized by the technical processes from which their medium was enacted, even though the physical properties of their medium are causally dependent upon these technical processes.
}

Manuscrito - Rev. Int. Fil., Campinas, v. 35, n. 2, p. 269-309, jul.-dez. 2012. 
attributing conceptual mental episodes in social practices, then VECME clearly endorses a post-ontological philosophy of mind (Ramberg, 2000). If by looking for the vehicles of CME we search for material entities that would be the realizers (exclusive, core or partial) of CME and that could be defined and described by their non-intentional properties, it is likely that CME do not have vehicles. Ultimately, our externalist strategy leads us to defend a vehicleless externalism on conceptual mental episodes, in the following sense:

1) CME do not have intracranial vehicles (they cannot have intracranial vehicles, and do not need to have intracranial vehicles);

2) CME primarily have owners,

3) Intentionally irreducible entities such as sayings and doings (and propensities to say and to do) might be considered as vehicles of CME, but parasitically on the identification of their owners, and only as the supervenience basis of these CME.

CME primarily have owners: persons as members of social practices. Conceptual mental episodes are owned by persons behaving appropriately in conceptual practices. A person is more than an organism or than a set of organs: as an agent, it is capable of evaluating its goals and actions with reference to norms or standards of correctness. An organism is made of organs and subpersonal parts, but a person is not constituted by subpersonal entities. Persons are persons in virtue of being acknowledged as such in social and institutional practices. As Wilfrid Sellars said,

to think of a featherless biped as a person is to think of it as a being with which one is bound up in a network of rights and duties. (...) To think of a featherless biped as a person is to construe its behaviour in terms of actual or potential membership in an embracing group each member of which thinks of itself as a member of the group (...) The conceptual framework of persons is the framework in which we think of one another as sharing the community intentions which provide the ambience of principles and standards (above all, those which make 
meaningful discourse and rationality itself possible) within which we live our own individual lives. (1963, p.39-40)

Of course, judgments involve the production and the use of non-intentionally specifiable entities (be they subpersonal, or artifacts), but they are defined as relational properties, as properties dependent on what a person is being taken as. From that perspective, asking where or what are the vehicles of judging that $p$ is as strange as looking for the vehicles in virtue of which one is a mayor or is a spouse. Nobody is a mayor or a spouse in virtue of the possession of intrinsic physiological properties, or of the possession of some artifact (although, of course, physiological properties and artifacts are involved when one becomes a spouse or a mayor, or exhibits that status by being taken as a mayor or as a spouse).

In some places, Anthony Kenny (2009, 1995) has proposed another understanding of what the relations between mind, mental abilities (what we call here inferential behaviour, occurrent and dispositional) and concrete physical structures that can be located and measured (named by Kenny "vehicles") might be, but depending on another sense of "vehicle". Indeed, for Kenny, a vehicle is "the physical ingredient or structure in virtue of which the possessor of an ability possesses the ability and is able to exercise it" (Kenny, 1995, p.44). In that context, a vehicle is not the (putative) realizer of a CME; it is an enabling condition of the fact an agent is able to exhibit inferential behaviour and thus, for Kenny, to possess a mind. Vehiclereductionism, in Kenny'sense, is the attempt to identify mental capacities (here: inferential behaviour, dispositional or occurrent) to the vehicles in virtue of which we possess those capacities.

In Kenny's sense, we can accept that CME have vehicles. Saying that CME have (Kenny-defined) vehicles amounts to saying that there are physical structures and processes in virtue of which we can manifest the inferential behaviour that, once taken as correct in virtue of prevailing inferential norms and linguistic practices, can be seen as a criterion of the presence of CME. 
But we must be careful: the vehicles of CME, in Kenny's sense, are not restricted to cerebral structures and processes ${ }^{16}$ : indeed, inferential capacities can notably be possessed and exercised in virtue of the use of artifacts or other persons. These vehicles are not brain-bound, but they should definitely not be confused with vehicles as they have been defined here, according to orthodox philosophy of $\operatorname{mind}^{17}$, as realizers of mental phenomena.

One of the striking - and puzzling - consequences of that kind of externalism are its prospects for mental causation. From the perspective of VECME, CME are not causes of behaviour: it is rather the production of appropriate behavioural performances that can legitimate the attribution and thus the existence of the CME. $S \operatorname{did} M$ because he judged that $p$, and $\mathrm{S}$ judged that $p$ because, inter alia, he did $M$ (besides being disposed to produce other inferential performances). Taking this circularity seriously means that the explanation of $S$ 's behaviour by referring to the judging of $p$ does not need to entail an ontological commitment to the existence of some intracranial vehicle meaning that $p$. The explanation of $S$ 's behaviour by referring to the judging of $p$ is a causal explanation, but does not necessarily mirror an objective (i.e. explanation-independent) relation obtaining between intracranial items and observable behaviour (Hornsby, 1997, p.173; Dennett, 1991, n.11). For VECME, CME do not exist independently of our social practices of deontic scorekeeping, including explanatory practices, so that mental causation is also not independent of those practices. Obviously, that point stands in need of further clarification, and constitutes a topic for future work (see also Rudder-Baker, 1993, and Burge, 1993 for preliminary considerations about the possibility of

\footnotetext{
${ }^{16}$ Contrary to what Kenny seems to suppose, when he writes that « the vehicle of the human mind is, very likely, the human brain » (1995, p.44).

17 Including proponents of the Extended Mind Hypothesis (Clark and Chalmers, 1998), since (extended) vehicles, in the context of that hypothesis, are still understood as realizers of mental states.
}

Manuscrito - Rev. Int. Fil., Campinas, v. 35, n. 2, p. 269-309, jul.-dez. 2012. 
accounting for "mental causation" in a way that is compatible with VECME and its post-ontological commitments). But we should also remark that, notoriously, vehicle-internalism faces important problems about mental causation. If CME are realized into non-intentionally specifiable vehicles, and the causal properties of these vehicles are only inherited from their non-intentional properties, then how could the semantic properties of CME enjoy some autonomous causal efficacy? Put otherwise, if CME - as intentional states - have causal efficacy via the causal efficacy of their neural realizers, what is their raison d'etre in some internalist and physicalist ontology? One meets the problem of the alternative between epiphenomenalism and causal-explanatory exclusion (Kim, 1998). As suggested in the former section, this challenge was fatal to a theory of CME quite close to VECME, Davidson's anomalous monism.

The explanatory requirements that proponents of VECME face regarding the issue of mental causation are thus not more important and demanding than the ones that proponents of vehicleinternalism face. And there is even more than that: by putting CME out of our heads, in our social practices of deontic scorekeeping, proponents of VECME would be unmoved by the possible prospects of neural eliminativism, according to which the ontology of neural processes would ultimately be incompatible with the idea that CME could have intracranial vehicles (neat and well-defined neural entities standing in a one-to-one correspondence with them) (Ramsey, Stich and Garon, 1990). Proponents of VECME would not be shocked by the consequences of eliminativism, since they endorse a postontological philosophy of mind, as defined above: having a contentful mind is a matter of social deontological practices, and not of ontological facts. The constitutive conditions of our mindedness (conceptual mental life) need to be spelled out in terms of institutions (Descombes, 1995), and not in terms of scientific descriptions that would ultimately vindicate or not their existence. This is not the case for friends of vehicle-internalism (including DAM). Indeed, if eliminativism is true, 
they would have to accept that CME do not exist at all, since nothing would correspond to them in the intracranial world, where they were supposed to be ${ }^{18}$.

\section{REFERENCES}

ARMSTRONG, D.M.; MALCOLM, N. Consciousness and causality: A debate on the nature of mind. Oxford: Blackwell, 1984.

BRANDOM, R. "Freedom and constraint by norms". American Philosophical Quarterly, 16 (3), pp. 187-196, 1979.

. Making it explicit. Reasoning, representing, and discursive commitment. Cambridge (MA)/London: Harvard University Press, 1994.

. Articulating reasons. An introduction to inferentialism. Cambridge (MA)/London: Harvard University Press, 2000.

(Ed.). Rorty and his critics. Oxford: Blackwell, 2000.

. Tales of the mighty dead. Historical essays in the metaphysics of intentionality. Cambridge, MA/London: Harvard University Press, 2002.

. "From a critique of cognitive internalism to a conception of objective spirit: Reflections on Descombes'anthropological holism". Inquiry, 47, pp. 236-253, 2004.

Between saying and doing. Towards an analytic pragmatism. New York: Oxford University Press, 2008.

18 Acknowledgments : Thank you to three anonymous reviewers of Manucrito for their remarks, objections and encouragements. Parts of this paper were presented in Genoa ("Towards Analytic Pragmatism" Conference, 2009) and Prague ("Normativity of Meaning" Conference, 2011). I thank the audience for their remarks, objections and encouragements.

Manuscrito - Rev. Int. Fil., Campinas, v. 35, n. 2, p. 269-309, jul.-dez. 2012. 
BURGE, T. "Mind-body causation and explanatory practice". In: J.Heil and A.Mele (eds.) (1993), pp.97-120.

CLARK, A. "Material symbols". Philosophical Psychology, 19 (3), pp. 1-17. 2006.

CLARK, A.; CHALMERS, D. "The extended mind". Analysis, 58, pp. 10-23, 1998.

COLLINS, A. The nature of mental things. Notre Dame (Indiana): University of Notre Dame Press, 1987.

DAVIDSON, D. Essays on actions and events. Oxford: Clarendon Press, 1980. Press, 1974.

- "Knowing one's own mind". Proceedings and Addresses of the American Philosophical Association, 61, pp. 441-58, 1987. 3-17.

1999. "Reply to Bruce Vermazen". In: L. Hahn (ed.) (1999), pp. 653-655.

Truth, language and history. Oxford: Clarendon Press, 2005.

DENNETT, D. "Real patterns". Journal of Philosophy, vol.LXXXVIII, n¹, pp. 27-51, 1991.

DESCOMBES, V. La denrée mentale. Paris: Minuit, 1995. English translation by S.Schwartz, The mind's provisions: a critique of cognitivism. Princeton University Press, 2001.

EGIDI, R. (ed.), Wittgenstein: Mind and Language. Kluwer, 1995.

EVANS, G. The varieties of reference. Edited by J.McDowell. Oxford: Clarendon Press, 1982. 
FODOR, J.; LEPORE, E. The compositionality papers. Oxford: Oxford University Press, 2002.

GIBBARD, A. "Meaning and normativity". Philosophical Issues, 5, pp. 95115, 1994.

HACKER, P.M.S. Human nature: the categorial framework. Blackwell, Oxford, 2007.

, GLOCK, H.-J.; HYMAN, J. (eds.). Wittgenstein and Analytic Philosophy: Essays for P.M.S. Hacker. Oxford: Oxford University Press, 2009.

HAHN, L. (Ed.). The Philosophy of Donald Davidson. Chicago/La Salle: Open Court, 1999.

HAUGELAND, J. Having thought: Essays in the metaphysics of mind. Cambridge, MA/London: Harvard University Press, 1998.

HEIL, J.; MELE, A. (Eds.), Mental Causation. Oxford: Clarendon Press, 1993.

HORNSBY, J. Simple mindedness. In defense of naïve naturalism in the philosophy of mind. Cambridge, MA/London: Harvard University Press, 1997.

JACOB, P. What minds can do. Cambridge University Press, 1997.

KENNY, A. The metaphysics of mind. Oxford, Oxford University Press, 1989.

. "Cognitive scientism". In: P. M. S. Hacker, Hans-Johann Glock \& John Hyman (eds.) (2009).

Wittgenstein on mind and metaphysics. In: R.Egidi (ed.) (1995), pp. 37-46.

KIM, J. "The myth of nonreductive materialism". Proceeding of APA, 63/3, pp. 31-47, 1989. 
- Supervenience and mind. New York: Cambridge University Press, 1993.

- "Can supervenience and 'non-strict laws' save anomalous monism?” In: J. Heil and A. Mele (eds.) (1993), pp.19-26. . Mind in a physical world. Cambridge (MA): MIT Press, 1998.

-. "Supervenience, emergence, realization, reduction". In: M. Loux and D. Zimmerman (eds.) (2003), pp. 556-584.

KLAGGE, J. "Supervenience: ontological and ascriptive". Australasian Journal of Philosophy, Vol.66, N4, pp. 461-470, 1988.

LANCE, M. "The word made flesh: Toward a neo-Sellarsian view of concepts and their analysis". Acta Analytica, 15 (25), pp. 117-135, 2000.

LOUX, M.; ZIMMERMAN, D. (eds.). The Oxford Handbook on Metaphysics. New York: Oxford University Press, 2003.

MALCOLM, N. Nothing is hidden. Blackwell, 1989.

MCCULLOCH, G. The life of the mind. An essay on phenomenological externalism. London and New York: Routledge, 2003.

MCDOWELL, J. Meaning, knowledge \& reality. Cambridge (MA)/London: Harvard University Press, 1998a.

Mind, value \& reality. Cambridge (MA)/London: Harvard University Press, 1998b.

MCGINN, C. “The structure of Content". In: A. Woodfield (ed) (1982).

MCLAUGHLIN, B. "Type epiphenomenalism, type dualism, and the causal priority of the physical". Philosophical Perspectives, 3, pp. 109135, 1989. 
On Davidson's response to the charge of epiphenomenalism. In. J. Heil and A. Mele (eds.) (1993), pp. 2740.

MARRAS, A. "Methodological and ontological aspects of the mental causation problem". In: S. Walter and H. Heckmann (eds) (2003).

PEREGRIN, J. "Meaning as an inferential role". Erkenntnis, 64, pp. 136, 2006.

RAMBERG, B. "Post-ontological philosophy of mind: Rorty versus Davidson”. In: R. Brandom (ed.) (2000), pp. 351-370.

RAMSEY, W.; STICH, S., and GARON J. "Connectionism, eliminativism and the future of folk psychology". Philosophical Perspectives 4, pp. 499-533, 1990.

RIDDOCH, M.J.; HUMPHREYS, G.W. "Visual object processing in optic aphasia: A case of semantic access agnosia". Cognitive Neuropsychology, 4, pp. 131-185, 1987.

ROWLANDS, M. Externalism: Putting Mind and World Back Together Again. Chesham: Acumen, 2003.

RUDDER-BAKER, L. Saving belief: a critique of physicalism. Princeton: Princeton University Press, 1987.

. "Metaphysics and mental causation". In: J. Heil and A. Mele (eds.) (1993), pp. 75-95.

SEDIVY, S. "Minds: contents without vehicles". Philosophical Psychology 17 (2), pp. 149-181, 2004.

SELLARS, W. Science, Perception and Reality, London: Routledge \& Kegan, 1963.

. "Meaning as Functional Classification". Synthese, 27, pp. 417437, 1974. 
SHOEMAKER, S. Physical realization. New York: Oxford University Press, 2007.

SOSA, E. "Davidson's thinking causes". In: J. Heil and A. Mele (eds.) (1993), pp. 41-50.

STICH, S. From folk psychology to cognitive science. Cambridge (MA)/London: MIT Press, 1983.

WALTER, S.; HECKMANN, H. (Eds). Physicalism and Mental Causation: The Metaphysics of Mind and Action. Exeter: Imprint Academic, 2003.

WILSON, R. Boundaries of the mind: the individual in the fragile sciences. Cambridge University Press, 2004.

WITTGENSTEIN, L. Philosophical investigations. English translation by E.Anscombe. Oxford: Blackwell, 1953.

- Blue and Brown Books. Oxford: Blackwell, 1958.

. Last writings on the philosophy of psychology, vol. 1. G.H. von Wright and H. Nyman (eds.), C.G. Luckhardt (trans.). Oxford: Blackwell, 1982. Wittgenstein's lectures on philosophical psychology, 1946-47. Notes by P. T. Geach, A. C. Jackson, and K. J. Shah. Edited by P.Geach. University of Chicago Press, 1988.

WOODFIELD, A. (Ed). Thought and Object. Oxford: Clarendon Press, 1982.

WRIGHT, C. Realism, meaning and truth. Oxford: Blackwell, 1987. 